\title{
Quantification of disorders in obstetrics needing intensive care in a low resource setting
}

\begin{abstract}
Background: Many disorders can occur during pregnancy, labour, postpartum. Some women become normal, some seriously ill and some die. It is essential to know disorders' burden.

Objectives: of present study were to know burden of disorders, which cause severe illnesses, during pregnancy, birth, post birth, profile of such cases.

Material Methods: Analysis of profile of cases admitted over 5 years at rural referral institute was done. Criteria was admission to intensive care area with system for ventilatory support in obstetric department.

Results: Majority of women were of 20-29 years, mean age 24 years, $2.6 \%$ adolescents. $39.7 \%$ were rural, $36.2 \%$ urban, $24.1 \%$ from urban settlements with low resources, $69.7 \%$ were antenatal, $18.5 \%$ intranatal, $11.8 \%$ postnatal. Sixty two percent were nullipara. Severe morbidity had ' $U$ ' curve in relation to age. Hypertensive disorders (53\% of severely ill cases) were commonest basic disorder, next were medical disorders $(26 \%)$ (severe anaemia, heart disease, malaria, infective hepatitis, pneumonia). Others were, late haemorrhage $12 \%$, (antepartum and postpartum haemorrhage), early pregnancy complications(abortions, ectopic pregnancy, hydatiform mole) $5 \%$, puerperal sepsis $2 \%$, acute fatty liver of pregnancy $1.2 \%$, rupture uterus $0.8 \%$.

Conclusion: Severe maternal morbidity with reference to age followed a ' $U$ ' curve. More cases were primigravida. Highest ratio was of cases from low resource urban settlements. Majority of severely ill cases were antenatal, some postnatal too. Commonest primary cause of severe illness was hypertensive disorders, followed by medical disorders, haemorrhage, complications of early pregnancy, puerperal sepsis, acute fatty liver of pregnancy, rupture uterus in descending order. Quality maternal care, at primary level, timely referral, quality maternal care at referral is essential. Also a lot of research is needed for prevention of some disorders, their severity.
\end{abstract}

Keywords: quantification, disorders, intensive care, obstetric cases
Volume 9 Issue 2 - 2018

\author{
Shakuntala Chhabra,' Saima Ahmed, ${ }^{2}$ \\ Akanksha Suman, ${ }^{3}$ Mandar Karambelkar ${ }^{4}$ \\ 'Director Professor, Obstetrics Gynaecology, Mahatma Gandhi \\ Institute of Medical Sciences, India \\ ${ }^{2}$ Ex-postgraduate Student, Obstetrics Gynaecology, Mahatma \\ Gandhi Institute of Medical Sciences, India \\ ${ }^{3}$ Postgraduate Student, Obstetrics Gynaecology, Mahatma \\ Gandhi Institute of Medical Sciences, India \\ ${ }^{4}$ Ex-Assistant Professor, Obstetrics Gynaecology, Mahatma \\ Gandhi Institute of Medical Sciences, India
}

Correspondence: Chhabra S, Director Professor, Obstetrics Gynaecology, Mahatma Gandhi Institute of Medical Sciences, Sevagram, Wardha, India,

Email chhabra_s@rediffmail.com, schhabra@mgims.ac.in

Received: September 29, 2016 | Published: March 14, 2018

\section{Background}

Many disorders can occur during pregnancy, birth and post birth. Some women become normal others become severely ill and some even die. It is essential to know the disorders, burden of diseases which lead to severe illness and profile of women, who become severely ill. Latest definition for such severely ill cases, 'maternal near miss' is 'a woman who survives severe life threatening conditions, either after receiving emergency medical/surgical interventions or otherwise, during pregnancy, abortion, childbirth or within 42 days of pregnancy termination', ${ }^{1}$ based on existing definitions and a pilot study. ${ }^{2-5}$ Severe illnesses naturally occur more frequently than deaths, and so provide more robust information than maternal deaths. They provide information about the quality of care available at various levels, but place a significant burden on health resources. ${ }^{6-9}$ The reported incidence of MNM varies in different studies, and ranges from less than 1 per 1000 live births to 82 per 1000 live births..$^{2,9-13}$ Danel et al. ${ }^{14}$ reported some morbidity in $43 \%$ during hospitalization for delivery and $31 \%$ (1.2 million women) had at least one obstetric complication or at least 1 pre-existing medical condition. Despite substantial progress during the Millennium Development Goals, figures remain staggering 303000 women died due to pregnancy or childbirth- related causes. ${ }^{15}$

\section{Objectives}

Objectives of present study were to know the burden and causes of severe illnesses during pregnancy, birth\& post birth and profile of women who suffered severe illness.

\section{Material methods}

Analysis of critically ill obstetric cases managed over a period of 5 years in Obstetrics Gynaecology of Mahatma Gandhi Institute of Medical Sciences, a rural institute in central India was undertaken after approval of institute's ethics committee and consent of patient or accompanying relative. The inclusion criteria was, admission to intensive care area (ICA), which had facilities of 24-hours medical supervision, continuous vasoactive drug support\& mechanical ventilation. 5 The limitation of the present study was case identification not as per the recently developed definition of MNM,1 which evolved through a project in which author was also part of the team. But this study is also the base of working on the project, after which the MNM definition evolved.

During the study period, there were 32,655 obstetric admissions, 21,277 women delivered. Overall 455 women received intensive care, (study subjects). They accounted for $1.3 \%$ of obstetric admissions and $2.1 \%$ of births. 


\section{Results}

Of 455 critically ill pregnant, labouring, postpartum women, 180 (39.7\%) were rural, (1.1\% of overall rural obstetric cases), $165(36.2 \%)$ urban, $(1.2 \%$ of overall urban cases) and $110(24.1 \%)$ were from low resource urban areas, (3.3\% of all cases from such settlements). Twelve women $(2.6 \%)$ were in their teens, 393 (86.3\%) were of 20 29 years, no one was above 39 years, mean age was 24.16 years. Overall 317 women were antenatal, $(1.5 \%$ of all antenatal admissions and $69.7 \%$ of all severely ill cases), 84 were intranatal $(0.7 \%$ of all intranatal admissions, $18.5 \%$ of all severely ill) and 54 were postnatal (7.4\% of all postnatal admissions and $11.8 \%$ of all severely ill). Of 317 antenatal cases, 37 were of first trimester of pregnancy $(1.2 \%$ of all antenatal admissions of $1^{\text {st }}$ trimester of pregnancy, $12 \%$ of all severely ill antenatal cases, $8.1 \%$ of all severely ill), 34 women were of second trimester of pregnancy $(0.6 \%$ of all antenatal admissions of second trimester of pregnancy, $7.4 \%$ of all severely ill, $10 \%$ of all antenatal severely ill cases) and 246 of third trimester ( $2.6 \%$ of all admissions in third trimester of pregnancy, $78 \%$ of antenatal severely ill and $54 \%$ of severely ill). Two hundred and eighty two (62\% of all severely ill) were nullipara and $173(38 \%)$ were multipara, of which only 8 had more than two births and none was grand multipara [5 or more births].

Most common primary cause of severe illness was complications of hypertensive disorders. Overall $11.57 \%$ (3780 out of 32655 of all obstetric admissions) obstetric admissions were for hypertensive disorders and 239 (6.32\% of 3780 women with hypertensive disorders) were severely ill and required admission to ICA.

During the study period 381 obstetric cases were admitted with vaginal bleeding, 280 (73\%) cases of APH, 23 (8.2\% of all APH) of them were severely ill, [16 (14\% of 118 cases of placental abruption), $4(5.47 \%$ of 73 cases of placenta previa] and 3 of bleeding of unknown origin (BUO) (3.37\% of 89 cases of BUO). Overall APH accounted for

Table I Obstetric admissions and Maternal Morbidity

\begin{tabular}{|c|c|c|c|c|}
\hline \multirow{2}{*}{ Diagnosis } & & \multirow{2}{*}{ Total admissions with the disorders } & \multicolumn{2}{|c|}{ Cases of severe morbidity } \\
\hline & & & No. & $\%$ \\
\hline Ectopic & & 133 & 10 & 7.5 \\
\hline \multirow{2}{*}{ Abortion } & Septic & 12 & 4 & 33 \\
\hline & Spontaneous & 1119 & 4 & 0.35 \\
\hline \multirow[t]{2}{*}{ Hydatiform mole } & & 175 & 3 & 1.71 \\
\hline & Preeclampsia & 1042 & 66 & 6.33 \\
\hline \multirow{4}{*}{ Hypertensive disorder } & Preeclampsia + HELLP & 124 & 7 & 5.64 \\
\hline & Severely ill eclampsia & 152 & 125 & 80 \\
\hline & Eclampsia + HELLP & 14 & 14 & 100 \\
\hline & Placenta previa & 73 & 4 & 5.47 \\
\hline \multirow[t]{2}{*}{ Ante-partum haemorrhage } & Placental abruption & 118 & 16 & 13.55 \\
\hline & Buo & 89 & 3 & 3.37 \\
\hline \multicolumn{2}{|l|}{ Rupture uterus } & 6 & 4 & 66.66 \\
\hline \multirow{2}{*}{ Post-partum haemorrhage } & Atonic & 66 & 21 & 31.81 \\
\hline & Traumatic & 35 & 9 & 25.71 \\
\hline \multirow[t]{2}{*}{ Puerperal sepsis } & & 12 & 8 & 66 \\
\hline & Heart disease & 138 & 61 & 44.2 \\
\hline \multirow[t]{2}{*}{ Medical disease } & Anaemia & 324 & 37 & $\mid \mathrm{I} .4 \mathrm{|}$ \\
\hline & Infection & 1595 & 19 & 1.19 \\
\hline \multicolumn{2}{|l|}{ AFLP } & 10 & 3 & 30 \\
\hline \multicolumn{2}{|c|}{ Gynaecological disorders with pregnancy } & 70 & 4 & 5.71 \\
\hline \multicolumn{2}{|c|}{ Total } & 5307 & 422 & 7.95 \\
\hline
\end{tabular}

BUO, bleeding of unknown origin;AFLP, acute fatty liver of pregnancy.

$5.05 \%$ ( 23 of 455 ) of burden of severe illness. One hundred and one cases ( $26.5 \%$ of 381 cases of vaginal bleeding) were of PPH, 30 (29.7 $\%$ of all cases of PPH (101)) were severely ill, 9 of 35 (26\%) cases of traumatic PPH \& 21 of 66 (32\%) of atonic PPH. They accounted for $11.6 \%$ of all severely ill cases.

Over all 2057 women were admitted with medical disorders, 117 $(5.6 \%)$ of them were severely ill, 37 (11.4\%) of 324 of severe anaemia (18 iron deficiency, 12 haemolytic and 7 dimorphic anaemia). Of 138 cases admitted with cardiac disorders, 61 (44\%) were severely ill (55 valvular heart disease \& 6 cardiomyopathy). Nineteen (1.1\%) of 1595 women with various other medical disorders were severely ill (8 malaria, 6 hepatitis, 5 pneumonia).

During the study period 1723 women were admitted with abortion related problems, including $12(0.69 \%$ of all abortions $)$ of septic abortion, $8(66 \%)$ of 12 were severely ill, (4 cases of spontaneous and 4 cases of induced abortion). On the whole abortion complications were responsible for $1.75 \%$ burdens of severely ill cases (Table 1) (Figure 1).

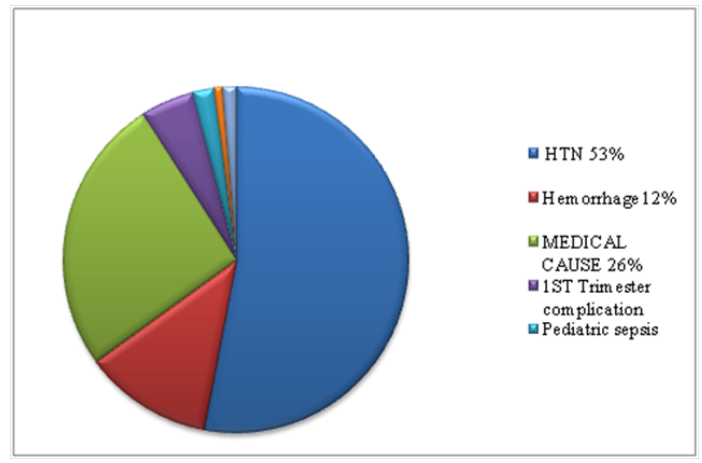

Figure I Distribution of Severe Maternal Morbidity. 
Ten $(7.5 \%)$ of 133 women who had ectopic pregnancy were severely ill $(2.2 \%$ of all severely ill cases). Three (1.71\% overall of 175 cases of molar pregnancy) of molar pregnancy were severely ill. Eight of 12 women with puerperal sepsis (P. sepsis) were severely ill ( $1.75 \%$ of severely ill). Four (5.6\% of 71 cases of all gynaecological disorders (gyn dis) with pregnancy were severely ill, $0.87 \%$ of all severely ill cases), were severely ill (Table 2).
Overall most common primary cause of severe illness was complications of hypertensive disorders, 239 (52.7\% of all severely ill), [82\% of eclampsia without HELLP, $100 \%$ of eclampsia with HELLP, $6.3 \%$ of all preeclampsia, $5.6 \%$ of all preeclampsia with HELLP].The second most common cause of severe illness was medical disorders, 117 cases ( $25.7 \%$ of severely ill), heart disease, 61 (13.4 \% of severely ill cases), severe anaemia, 37 (8.1\% of severely ill), infections 19 (4.17\% of severely ill) (Table 3$)$.

Table 2 Maternal Morbidity with Age, Parity, Gestation ( $\leq 13$ weeks) and Primary Diagnosis

\begin{tabular}{|c|c|c|c|c|c|c|c|c|c|c|c|}
\hline \multirow[b]{2}{*}{ Age } & \multirow[b]{2}{*}{ Parity } & \multicolumn{4}{|c|}{ abortion } & \multicolumn{3}{|c|}{ Medical diseases } & \multirow[b]{2}{*}{ Gynae disorders } & \multirow{2}{*}{\multicolumn{2}{|c|}{ Others Total }} \\
\hline & & Ectopic & & $\begin{array}{l}\text { eptic } \\
\text { ont Induced }\end{array}$ & Spont & H. Mole & Heart disease & Severe anaemia & & & \\
\hline \multirow{2}{*}{$<19$} & $\mathrm{~N}$ & 2 & & & & & & & & & 2 \\
\hline & $3-5$ & & & & & & & & & & \\
\hline \multirow{2}{*}{$20-29$} & $\mathrm{~N}$ & 6 & 1 & 2 & 2 & 3 & 2 & 5 & 4 & I & 27 \\
\hline & $3-5$ & & 1 & & & & I & & & & 2 \\
\hline \multirow{2}{*}{$30-39$} & $\mathrm{~N}$ & 2 & & & & & & & & & 2 \\
\hline & $\mathrm{I}-2$ & & & & 2 & & 4 & & & & 6 \\
\hline Total & & 10 & 2 & 2 & 4 & 3 & 7 & 5 & 4 & I & 39 \\
\hline
\end{tabular}

Spont, spontaneous; $\mathrm{H}$, Hydatiform.

Table 3 Maternal Morbidity with Age, Parity, Gestation (14-28 weeks, >28 weeks, in labor, post partum) and Primary Diagnosis

\begin{tabular}{|c|c|c|c|c|c|c|c|c|c|c|c|c|c|c|c|c|}
\hline \multirow[b]{2}{*}{ Age } & \multirow[b]{2}{*}{ Parity } & \multicolumn{4}{|c|}{ Hypertension } & \multirow[b]{2}{*}{ APH } & \multicolumn{4}{|c|}{ Medical diseases } & \multirow{2}{*}{$\begin{array}{l}\text { P. } \\
\text { SEPSIS }\end{array}$} & \multirow{2}{*}{$\begin{array}{l}\text { Rupture } \\
\text { Uterus }\end{array}$} & \multicolumn{2}{|c|}{$\begin{array}{l}\text { Post Partum } \\
\text { Hemorrhage }\end{array}$} & \multirow{2}{*}{ Others } & \multirow{2}{*}{ Total } \\
\hline & & PE & PE+ HELLP & EC & $\begin{array}{l}\text { EC+ } \\
\text { HELLP }\end{array}$ & & $\begin{array}{l}\text { Heart } \\
\text { disease }\end{array}$ & $\begin{array}{l}\text { Severe } \\
\text { anaemia }\end{array}$ & $\begin{array}{l}\text { Infection } \\
\text { a }\end{array}$ & AFLP & & & Ato & c Traumatic & & \\
\hline \multirow[t]{2}{*}{$<19$} & $\mathrm{~N}$ & 2 & & 5 & & & & & 3 & & & & & & & 10 \\
\hline & $\mathrm{N}$ & 44 & 5 & 102 & 6 & 14 & 16 & 15 & 5 & 3 & & & 7 & 4 & I & 222 \\
\hline \multirow[t]{3}{*}{ 20-29 } & $\mathrm{I}-2$ & 18 & 2 & 35 & 6 & 5 & 24 & 15 & 8 & & 8 & 4 & 12 & 5 & 3 & 145 \\
\hline & $3-5$ & & & 2 & & 3 & & & & & & & & & & 5 \\
\hline & $\mathrm{N}$ & 2 & & 3 & & & 6 & & 3 & & & & & & & 14 \\
\hline \multirow[t]{2}{*}{$30-39$} & I-2 & & & 3 & 2 & 1 & 8 & & & & & & 2 & & & 16 \\
\hline & $3-5$ & & & 2 & & & & 2 & & & & & & & & 4 \\
\hline Total & & 66 & 7 & 152 & 14 & 23 & 54 & 32 & 19 & 3 & 8 & 4 & 21 & 9 & 4 & 416 \\
\hline
\end{tabular}

$\mathrm{PE}$, preeclampsia; $\mathrm{EC}$, eclampsia; $\mathrm{APH}$, ante partum hemorrhage; AFLP, acute fatty liver of pregnancy; P, puerperal; PPH, post partum hemorrhage. Others- thyroid disease, surgical complications, trauma, bronchial asthma, amniotic fluid embolism

Fifty three (11.6\% of severely ill) cases were of haemorrhage, 23 (4.6\% of severely ill cases of APH) [16 (3.2\% of severely ill, of placental abruption, 4 (8.7\% of severely ill, placenta previa)] and 3 BUO ( $8.5 \%$ of all severely ill)] and 30 (6.5\% of severely ill) of PPH [21 (4.6\% of severely ill, atonic PPH) and $9(1.9 \%$ of severely ill, of traumatic $\mathrm{PPH})]$.

\section{Discussion}

Various disorders are known to occur during pregnancy, birth and post birth and will continue, till the time a lot more is known about these disorders. However, inspite of developing complications, some women do well, others become severely ill. While some aspects of, why some women become severely ill or why they die are known, ${ }^{16-18}$ many aspects are still not known. Present study was conducted to know quantification of disorders for which women needed intensive care and to know profiles of such severely ill women. It was revealed that $2.6 \%$ of women admitted with severe illness were of less than 20 years of age. Though most women who were severely ill, were of 20-29 years, and the mean age was 24 years. age had a 'U' curve. Prual et al. ${ }^{19}$ have also reported similar pattern of age distribution among cases with severe morbidity. The researchers reported that the main reasons for high morbidity and mortality during extremes of age were complications like hypertensive disorders of pregnancy, anaemia, more likely to occur in teenagers or in elderly.

Out of all the severely ill cases, $69.7 \%$ were antenatal, $18.5 \%$ intranatal and $11.8 \%$ postnatal. $62 \%$ of all severely ill were nullipara. Similar findings have been reported by Chhabra et al. ${ }^{20}$ This was in contrast with the studies in the developed countries where majority of the severely ill cases were postnatal. Lapinsky et al. ${ }^{21}$ reported $91 \%$ and, Baskett et al. ${ }^{22} 82 \%$ postnatal cases. May be preventable complications, during pregnancy \& labour are prevented and so ratio changes.

Further it was revealed that $39.7 \%$ women were rural, $36.2 \%$ urban and $24.1 \%$ were from low resource urban settlements and these figures represented $1.1 \%$ of all rural, $1.2 \%$ of all urban and $3.3 \%$ of all admissions from low resource urban areas. Out of all severely ill cases also, $44 \%$ were rural, $39 \%$ from low resource urban and $17 \%$ urban. In various studies in developing countries, it was revealed that maternal mortality ratio for such low resource urban settlements were higher than the national average. In a study done on maternal morbidity and mortality in Nairobi also, maternal mortality was found to be much more in such regions than the national average. The reasons highlighted 
by researchers were large number of unwanted pregnancies, lack of facilities for contraception, resulting in unsafe abortions and high incidence of anaemia, HIV and tuberculosis in pregnant women from such settlements. Okwemba et al. ${ }^{23}$ reported more than $50 \%$ teenagers, $70 \%$ below poverty line and majority illiterate with no antenatal checkup. In the present study though insignificant difference ( $\mathrm{P}$ value >.05) compared to low resource urban settlements among rural case, ratio was low. Villages have homogenous population, may be better environment and better compliance by women. So urban with low resources are the worst sufferers.

In the present study the commonest primary cause of severe illness was hypertensive disorders, which accounted for $53 \%$ of all severely ill cases. This was followed by medical disorders (26\%). Medical disorders leading to severe illness were severe anaemia, heart disease, malaria, infective hepatitis and pneumonia. The third leading cause was haemorrhage $(12 \%)(\mathrm{APH}, \mathrm{PPH})$ followed by complications related to early pregnancy (5\%), (abortion, ectopic pregnancy and hydatiform mole), puerperal sepsis $2 \%$, acute fatty liver of pregnancy $1.2 \%$ and rupture uterus $0.8 \%$.

Consistent with the present study the most common diagnosis among women, admitted in the ICA at a referral center in Africa were complications of pregnancy induced hypertension which accounted for $60 \%$ of all admissions. In the same study, hemorrhage was the second most common cause for admission to ICA. ${ }^{24}$ Mantel et al. ${ }^{10}$ reported, the most common initiating obstetric conditions were hypertension in $26 \%$; haemorrhage in $26 \%$; and abortion or puerperal sepsis in $20 \%$. Lotufo et al. ${ }^{25}$ reported that hypertension was the main cause of admission for potentially life-threatening conditions; however, hemorrhage was the main cause of MNM and deaths at their institution, suggesting that delays may occur in implementing appropriate obstetric care. In a study by Bibi et al. ${ }^{26}$ at a tertiary health center in Pakistan, pre-eclampsia and eclampsia were the leading causes of maternal ill health and sepsis was the second most common cause. Khosla et al. ${ }^{27}$ reported that of 5124 deliveries during the study period, there were 224 cases of near-miss. Eclampsia and pregnancyrelated sepsis were the major causes for maternal mortality and near-miss. In the present study, medical disorders were the second leading cause of severe illness. In two separate studies of critically ill obstetric cases by Mahutte et al. ${ }^{28}$ and Baskett et al., ${ }^{22}$ obstetric hemorrhage, hypertension, cardiac disease, respiratory complications and infections were the five main reasons for ICU admission and were responsible for more than $80 \%$ cases of severe illness. Panchal et al. ${ }^{29}$ have also reported similar reasons for severe illnesses, however their relative ratio were different, eclampsia $36.6 \%$, PPH $28.3 \%$, APH $15.8 \%$, pulmonary complications $13.5 \%$ and infection $5.2 \%$.

Jabir et al. ${ }^{30}$ reported relative ratio of hemorrhage $40.8 \%$, infection $21.5 \%$, hypertensive disorders $18.0 \%$, anaemia $11.8 \%$ and dystocia $7.9 \%$. The proportion of various disorders was different. In the present study after hypertensive disorders, it was medical disorders, not haemorrhage. Taly et al. ${ }^{31}$ reported hemorrhage as the leading cause of severe illness. Simkhada et al. ${ }^{32}$ reported PPH responsible for $46 \%$ cases of mortality and morbidity, obstructed labor for $16 \%$ and eclampsia $14 \%$.

In African countries, sepsis is diagnosed ten times more often than in Great Britain, France and Canada. ${ }^{33-35}$ In the present study 12 cases were admitted with puerperal sepsis of them, 8 were severely ill.

We had difficulty in categoring cases with more than one disorder like, severe anaemia associated with other conditions in $19 \%$ of cases. Study by Chhabra et al. ${ }^{36}$ revealed anaemia in $22 \%$ cases. The WHO systematic review of causes of maternal morbidity has shown anaemia as the cause in $12.8 \%$ of maternal deaths in Asia, 3.7 \% in Africa and none in developed countries. Khan et al. ${ }^{37}$ reported role of anaemia as a cause of maternal morbidity underestimated.

In the present study there were 7 cases of severe illness due to abortion, severity was more when sepsis was associated with development of RDS. Afessa et al..$^{38}$ reported that sepsis was the most common cause of Systemic Inflammatory Response Syndrome and organ failure in critically ill obstetric patients. Out of 455 critically ill patients 335(73.6 \%) were emergency admissions without proper antenatal care, $102(22.4 \%)$ had reported once, but $18(4 \%)$ had reported to antenatal clinic 3 to 5 times. Role of quality antenatal care in preventing severe illness during pregnancy is well known. Bibi et al. ${ }^{26}$ reported, $96 \%$ of women with severe morbidity unbooked similar to the present study. Karnad et al. ${ }^{39}$ reported two preventable factors that adversely affected maternal morbidity, mortality at their centre, inadequate utilization of antenatal services and delay in receiving adequate care.

If severe maternal morbidity is to be prevented, it is essential to keep on auditing \& take targeted approach. The difference in prevalence of disorders with several illnesses may be, largely due to non-identical levels of obstetric help or other reasons. Depending upon which disorders are responsible for severe illness and fatality, actions need to be taken for preventing disorders, if disorders occur, preventing severe illnesses and deaths. Problems are global, solutions need to be local.

By studying the severely ill cases, a lot can be learnt about the processes in place (or lack of them) to deal with maternal health. Waterstone et $\mathrm{al}^{2}$ reported that severe obstetric morbidity and its relation to mortality may be more sensitive measure of pregnancy outcome than mortality alone. In the present study criteria of inclusion was admission to ICA which does not go with the patient inclusion criteria as per recent definition of MNM, ${ }^{1}$ the new definition is based on symptoms, signs and investigations and is the limitation of the present study. However, all severely sick patients were included in the study, the strength of the study. In order to reduce mortality rates, it is essential to understand disorders responsible for maternal morbidity, why severe illness occurs and pathway to death. Such studies help in knowing the disorders which need special attention for research, for care, so that initiatives, including addressing prevention, reducing the burden of morbidity can be taken.

\section{Conclusion}

Severe maternal morbidity with reference to age followed a ' $U$ ' curve. More women were primigravida. Also highest ratio was of cases of low resource urban settlements. Majority of the severely ill cases were antenatal, but severe illness occurred in postnatal period also. Commonest primary cause of severe illness was hypertensive disorders, followed by medical disorders, like severe anaemia, heart disease, malaria, infective hepatitis and pneumonia. Third cause was haemorrhage, followed by puerperal sepsis, acute fatty liver of pregnancy and rupture uterus.

It appears quality antenatal care, at primary level, timely referral quality intranatal, postpartum care at referral are essential. A lot of research is also needed.

\section{Acknowledgements}

None. 


\section{Conflicts of interest}

Authors declare there is no conflict of interest in publishing the article.

\section{References}

1. Purandare $\mathrm{C} 1$, Bhardwaj A, Malhotra M, et al. Maternal near-miss reviews: lessons from a pilot programme in India. BJOG. 2014;121(Suppl 4):105-11.

2. Waterstone M, Bewley S, Wolfe C. Incidence and predictors of severe obstetric morbidity: case-control study. BMJ. 2001;322(7294):1089-93.

3. Pattinson RC, Hall M. Near misses: a useful adjunct to maternal death enquiries. Br Med Bull. 2003;67:231-43.

4. Minkauskiene M, Nadisauskiene R, Padaiga Z, et al. Systematic review on the incidence and prevalence of severe maternal morbidity. Medicina (Kaunas). 2004;40(4):299-309.

5. World Health Organization. Evaluating the quality of care for severe pregnancy complications: The WHO near-miss approach for maternal health. Reproductive Health and Research, Geneva: World Health Organization, 2011. 34 p.

6. Zeeman GG, Wendel GD, Cunningham FG. A blueprint for obstetric critical care. Am J of Obstet Gynaecol. 2003;188(2):532-6.

7. World Health Organization. Beyond the numbers: reviewing maternal deaths and complications to make pregnancy safer. Reproductive Health and Research; Geneva: World Health Organization, 2004. 142 p.

8. Filippi V, Ronsmans C, Gohou V, et al. Maternity wards or emergency obstetric rooms? Incidence of near-miss events in African hospitals. Acta Obstet Gynecol Scand. 2005;84(1):11-6.

9. Oladapo OT, Sule-Odu AO, Olatunji AO, et al. "Near-miss" obstetric events and maternal deaths in Sagamu, Nigeria: a retrospective study. Repr Health. 2005;2:9.

10. Mantel GD, Buchmann E, Rees H, et al. Severe acute maternal morbidity: a pilot study of a definition for a near-miss. $\mathrm{Br} \mathrm{J}$ Obstet Gynecol. 1998;105(9):985-990.

11. Brace V, Penney G, Hall M. Quantifying severe maternal morbidity: a Scottish population study. Br J Obstet Gynecol. 2004;111(5): 481-484.

12. Wen SW, Huang L, Liston R, et al. Severe maternal morbidity in Canada, 1991-2001. CMAJ. 2005;173(7):759-764.

13. Sousa MH, Cecatti JG, Hardy EE, et al. Severe maternal morbidity (near miss) as a sentinel event of maternal death. An attempt to use routine data for surveillance. Repr Health. 2008;5:6.

14. Danel I, Berg C, Johnson CH, et al. Magnitude of maternal morbidity during labor and delivery: United States, 1993-1997. Am J Public Health. 2003;93(4):631-634.

15. Evelyn D, Zoë M, Andrea n, et al. The need for innovation and implementation research for maternal and newborn health. Lancet. 2016;388(10052):1374.

16. Say L, Pattinson RC, Gulmezoglu AM. WHO systematic review of maternal morbidity and mortality: the prevalence of severe acute maternal morbidity (near miss). Repro Health. 2004;1(1):3.

17. Jahan R. Securing maternal health through comprehensive reproductive health services: lessons from Bangladesh. Am J Public Health. 2007;97(7):1186-90.

18. World Health Organization. Maternal mortality in 2005: estimates developed by WHO, UNICEF, UNFPA, and The World Bank. Reproductive Health and Research, Geneva: World Health Organization, 2008. 48 p.
19. Prual A, Bouvier-Colle MH, Bernis LD, et al. Severe maternal morbidity from direct obstetric causes in West Africa: incidence and case fatality rates. Bull World Health Organ. 2000;78(5):593-602.

20. Chhabra P, Guleria K, Saini NK, et al. Pattern of severe maternal morbidity in a tertiary hospital of Delhi, India: a pilot study. Trop Doct. 2008;38(4):201-4

21. Lapinsky SE, Kruczynski K, Seaward GR, et al. Critical care management of the obstetric patient. Can J Anaesth. 1997;44(3):325-9.

22. Baskett TF, O Connell CM. Severe obstetric maternal morbidity: a 15year population-based study. J Obstet Gynecol. 2005; 25(1):7-9.

23. Okwemba A. Slums dwellers take lead on maternal deaths. African Woman and Child Feature Service, 2009.

24. Osinaike B, Amanor-Boadu S, Sanusi A. Obstetric Intensive Care: A Developing Country Experience. Internet J Anesth. 2006;10(2):1-5.

25. Lotufo FA, Parpinelli MA, Haddad SM, et al. Applying the new concept of maternal near-miss in an intensive care unit. Clinics (Sao Paulo). 2012;67(3):225-230.

26. Bibi S, Memon A, Sheikh JM, et al. Severe acute maternal morbidity and intensive care in a public sector university hospital of Pakistan. J Ayub Med Coll Abbottabad.2008;20(1):109-12.

27. Khosla AH, Dahiya K, Sangwan K. Maternal mortality and'near-miss' in rural north India. Int J Gynecol Obstet. 2000;68(2):163-164.

28. Mahutte NG, Murphy-Kaulbeck L, Le Q, et al. Obstetric admissions to the intensive care unit. Obstet Gynecol. 1999;94(2):263-6.

29. Panchal S, Arria AM, Harris AP. Intensive care utilization during hospital admission for delivery: prevalence, risk factors, and outcomes in a statewide population. Anesthesiology. 2000;92(6):1537-44.

30. Jabir M, Abdul-Salam I, Suheil DM, et al. Maternal near miss and quality of maternal health care in Baghdad, Iraq. BMC preg and childbirth. 2013;13:11

31. Taly A, Gupta S, Jain N. Maternal Intensive care and nearmiss mortality in Obstetrics. J Obstet Gynecol Ind. 2004;54(5):478-82.

32. Simkhada B, Van Teijlingen ER, Porter M, et al. Major problems and key issues in Maternal Health in Nepal. Kathmandu Univ Med $J$ (KUMJ). 2006;4(2):258-63

33. Prual A, Huguet D, Garbin O, et al. Severe obstetric morbidity of the third trimester, delivery and early puerperium in Niamey (Niger). African $J$ Repr Health. 1998;2(1):10-19.

34. De Bernis L, Dumont A, Bouillin D, et al. Maternal morbidity and mortality in two different populations of Senegal: a prospective study (MOMA survey). Br J Obstet Gynecol. 2000;107(1):68-74.

35. Vandecruys HI, Pattinson RC, Macdonald AP, et al. Severe acute maternal morbidity and mortality in the Pretoria Academic Complex: changing patterns over 4 years. Eur J Obstet Gynecol Reprod Biol. 2002;102(1):6-10.

36. Chhabra P, Guleria K, Saini NK, et al. Pattern of severe maternal morbidity in a tertiary hospital of Delhi, India: a pilot study. Trop Doct. 2008;38(4):201-4.

37. Khan KS, Wojdyla D, Say L, et al. WHO analysis of causes of maternal death: a systematic review. Lancet. 2006;367(9516):1066-74.

38. Afessa B MD, Green B, Delke I, et al. Systemic Inflammatory Response Syndrome, Organ Failure, and Outcome in Critically Ill Obstetric Patients Treated in an ICU.Chest.2001;120(4):1271-7.

39. Karnad DR, Lapsia V, Krishnan A, et al. Prognostic factors in obstetric patients admitted to an Indian intensive care unit. Critical Care Med. 2004;32(6):1294-9. 